\title{
Take My Advice-I Am Not Following It: Ad Hominem Arguments as Legitimate Rebuttals to Appeals to Authority
}

Moti MizRAHI

Department of Philosophy

Hunter College CUNY

695 Park Ave.

New York, NY 10065

Email:mmizrah@hunter.cuny.edu

\begin{abstract}
In this paper, I argue that ad hominem arguments are not always fallacious. More explicitly, in certain cases of practical reasoning, the circumstances of a person are relevant to whether or not the conclusion should be accepted. This occurs, I suggest, when a person gives advice to others or prescribes certain courses of action but fails to follow her own advice or act in accordance with her own prescriptions. This is not an instance of a fallacious $t u$ quoque provided that such circumstantial ad hominem arguments are construed as rebuttals to appeals (administrative) authority (of expertise), or so I argue.
\end{abstract}

Résumé:

Keywords: abusive ad hominem, administrative authority, appeal to authority, argument from authority, argumentum ad hominem, argumentum ad verecundiam, circumstantial ad hominem, tu quoque

\section{Introduction}

In most textbooks, arguments against the person (argumentum ad hominem) are considered fallacious for the most part. The phrase ad hominem is commonly used to name the fallacy of attacking the person who makes a certain claim rather than the claim itself. For instance, according to Copi and Cohen (1998, p. 166), the phrase ad hominem names a "fallacious attack in which the thrust is directed, not at a conclusion, but at the person who asserts or defends it."

According to Copi and Cohen, the ad hominem fallacy has two major forms: abusive and circumstantial. In an abusive ad hominem,

(C) Moti Mizrahi. Informal Logic, Vol. 30, No. 4 (2010), pp. 435-456. 
the character of the person who asserts a certain claim is under attack. It is then argued that, since the character of the person who makes the claim is "defective" in some way, what she claims must be incorrect, wrong, unreasonable, etc. This is a fallacy, according to Copi and Cohen, because abusive premises are irrelevant to the truth or falsity of what the person with the alleged "bad" character is claiming.

In a circumstantial ad hominem, it is not the character of the person that is under attack but her circumstances. For example, it might be argued that the circumstances of a person, such as her nationality or employment, commit her to a certain view on pain of inconsistency. Again, this is a fallacy, according to Copi and Cohen, because the circumstances of a person making a certain claim are irrelevant to the truth or falsity of that claim.

It is not clear, however, whether or not ad hominem arguments are always fallacious. ${ }^{1}$ For instance, according to Salmon, there are circumstances in which legitimate ad hominem arguments can occur. For Salmon, ad hominem arguments conclude that a statement is false because it is made by a particular person or group of persons. Salmon (2007, p. 121) says that "Such arguments are legitimate only when there is reason to believe that most of the claims made by the individual or group concerning a particular aspect of that subject matter are false." 2 Salmon construes correct ad hominem arguments as statistical syllogisms:

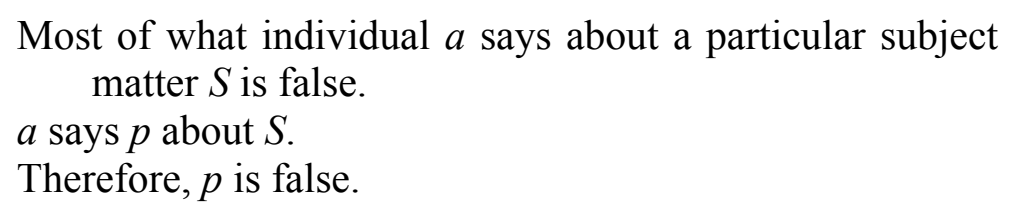

Most of what individual $a$ says about a particular subject matter $S$ is false.

$a$ says $p$ about $S$.

Therefore, $p$ is false.

Salmon (2007, p. 121) notes that "we are not often in a position to claim that most of what an individual says about a subject is false," since "few individuals lie about or are almost always wrong about a subject." She gives the following examples of circumstances in which legitimate ad hominem arguments can occur:

- $\quad$ against the pronouncements of scientific cranks;

- $\quad$ against the exaggerated claims of salespersons;

- $\quad$ against the credibility of witnesses who have lied under oath.

According to Salmon, then, ad hominem arguments are fallacious unless most claims made by the person or group in question on the subject matter in question are false. Salmon (2007, p. 122) points

\footnotetext{
${ }^{1}$ See, e.g., Hoaglund (1981, pp. 7-9).

${ }^{2}$ Cf. Mackenzie (1980, pp. 9-11).
} 
out that this "statistical premise is hardly ever true, so legitimate cases of arguments against the person are rare."

One such legitimate case, pointed out by a number of authors, is the courtroom tactic of impeaching a witness' testimony by attacking his or her credibility. For example, according to Walton (1995, p. 111):

Whether an ad hominem argument is reasonable or fallacious, in a particular case, depends on the context of dialogue. For an attorney to raise allegations about the bad moral character or character for veracity of a witness he is cross-examining in court can be a reasonable kind of ad hominem argumentation.

Indeed, Walton (2004, p. 361) prefers the term 'direct', rather than 'abusive', for the ad hominem argument, precisely because the latter "suggests that this form of argument is always fallacious."

According to Walton (1998, p. 213), the argumentation scheme for the direct ad hominem argument is the following:

$a$ is a person of bad (defective) character.

Therefore, $a$ 's argument should not be accepted.

Such direct ad hominem arguments may be legitimate, according to Walton (2004, p. 361), "because the attack on a respondent's [i.e., the person putting forward the original argument] character, say for honesty, sincerity or trustworthiness, can often undermine the respondent's credibility as a source." This is the case, Walton argues, when credibility as a source is a reason for accepting a claim. Again, the classic example is when "an attorney cross-[examines] a witness to attack the character of the witness for honesty" (Walton, 2004, p. 361).

In what follows, I discuss other cases of practical reasoning in which ad hominem arguments seem to be legitimate. That is to say, I wish to point to and make clear certain instances in which the circumstances of a person are relevant to the conclusion of the argument. First I will discuss several examples in order to illustrate the kind of circumstances I have in mind. Then I will propose that similar instances of ad hominem arguments of this sort are not fallacious ad hominem arguments when construed as rebuttals to appeals to (administrative) authority (of expertise).

\section{Do as I say, not as I do}

As mentioned above, Salmon proposes that an ad hominem argument can be construed as a statistical syllogism. If the statistical premise is true, then the argument is not fallacious. I would like to 
take another approach, however, and propose that there are other situations in which the circumstances of the person are relevant to the conclusion of the argument, even if we don't know that the statistical generalization actually holds. In what follows, I will argue that the circumstances of the person are especially relevant to the conclusion of the argument when the person in question is supposed to be an expert. Hence, when an appeal to authority is made, it might be relevant to mention the circumstances of the expert, for they might undermine her credibility as an expert. Unlike Walton's direct ad hominem, however, the attack in this case is not a direct attack on the expert's character, but an indirect one via her circumstances. $^{3}$

By way of illustration, consider the following: suppose that renowned moral philosopher $M$ argues vigorously in support of animal rights. In virtue of her expertise in moral matters pertaining to the appropriate treatment of animals, $M$ gives the following expert advice: "Do not torture animals." Suppose further that, after a while, we find out that $M$ has been eating red meat and wearing fur coats all along. Furthermore, we find out that $M$ has been arranging underground dog fights all this time. Would these circumstances, now coming to light, make us change our minds about $M$ 's expert advice? Would we think that $M$ 's advice should not be heeded? It might seem that, if we were to argue in this way, we would be committing the tu quoque fallacy. This fallacy is usually considered a variant of ad hominem arguments. An instance of tu quoque occurs when someone counters an attack on a particular view by accusing the person who holds it of being in a position similar to that being criticized. More colloquially, tu quoque amounts to responding to an ad hominem by saying something along the lines of "Look who's talking," "You're just the same," or "You're just as bad." For example, if you accuse me of being lazy for not doing my work, I might respond by saying that you cannot call me lazy because you have not finished any of the work you were assigned to do either.

Nevertheless, I propose that we should not dismiss the above scenario as an instance of tu quoque, and hence fallacious. I think that if we uncover the underlying assumptions that are involved in

\footnotetext{
${ }^{3}$ The notion of expertise raises several epistemological problems, especially in relation to testimony in the domain of science and the law. See, e.g., Kitcher (1993), Walton (1997), and Adler (2002). In this paper, I will try to steer clear of the epistemological problems. I will assume that the experts in question are indeed experts. However, as an anonymous referee of this journal pointed out, this assumption can be challenged, given the kind of examples I use. I will address this objection in Section 5. ${ }^{4}$ See, e.g., Walton (1998, p. 16).
} 
this kind of reasoning, then it may turn out to be not fallacious after all. In this case, the assumptions I have in mind are the following:

(a) that $M$ is an authority on moral matters, especially those pertaining to the appropriate treatment of animals, in virtue of being a moral philosopher;

and so,

(b) if $M$ says that we must not torture animals, then that is a good reason to follow her advice, or act in accordance with her prescriptions, given her expertise.

In other words, the sort of circumstantial ad hominem arguments I have in mind are legitimate rebuttals to appeals to authority, or so I argue.

Before I show how such circumstantial ad hominem arguments can be legitimate rebuttals to appeals to authority, a clarification is in order. There is a common distinction in the literature between two kinds of authority. For example, according to Walton (1992, p. 48):

one can distinguish between two kinds of authorityadministrative authority on the one hand and cognitive authority on the other-even though these two kinds of authority may be combined in the same individual in some cases. For example, a physician may be a cognitive authority, that is, an expert in the field of medicine, and an administrative authority whose standing as a licensed physician makes his or her rulings authoritative and binding on some questions. Usually the textbooks in logic have cognitive authority in mind when they cite cases of the fallacious argumentum ad verecundiam. ${ }^{5}$

Accordingly, Salmon (2007, p. 121), for instance, seems to have cognitive authority in mind when she construes appeals to authority as statistical syllogisms:

Most of what authority $a$ has to say about subject matter $S$ is correct.

$a$ says $p$ about $S$.

Therefore, $p$ is correct.

\footnotetext{
${ }^{5}$ Other authors seem to use a variety of terms for an intuitively similar distinction. See, e.g., Fox (1972), 'theoretical'/'practical'; Wilson (1983), 'cognitive'/'administrative'; De George (1985), 'epistemic'/'executive'.
} 
Construing appeals to administrative authority as statistical syllogisms might look roughly like this:

Most of what authority $a$ has to say about subject matter $S$

is good advice.

$a$ says that we should do $D$.

Therefore, we should do $D$.

I will argue that the kind of appeals to authority that may be legitimately rebutted by a circumstantial ad hominem is appeals to administrative authority. Throughout this paper, then, I will not be concerned with cognitive authority (i.e., the authority that puts forward statements), but rather with administrative authority (i.e., the authority that puts forward imperatives). As Goodwin (1998, pp. 268-269) puts it:

The former looks for the auditor to take what is stated as true and believe it, or at least give it weight. The latter looks for the auditor to take what is commanded and make it true, by making it what is decided, chosen, intended, willed-in short, for the auditor to do it. ${ }^{6}$

In that respect, it is important to note that, although it might be the case that administrative authority and cognitive authority are often deeply interconnected, this link can be ignored for present purposes. For present purposes, it is enough to recognize that they can be treated independently. For example, one might follow $M$ 's advice to refrain from torturing animals without believing that one should do so. Indeed, it seems that one might even be indifferent to the pain and suffering of animals, but still obey $M$ 's instruction to refrain from torturing animals, for other reasons. Perhaps one wants to impress a potential partner who is an advocate for animal rights. ${ }^{7}$ In the case of $M$, then, the appeal to authority is an appeal to administrative authority of the following sort:

$M$ : Do not torture animals!

$Q$ : Why?

$M$ : Because I say so, that's why! ${ }^{8}$

For present purposes, this appeal to administrative authority can be kept distinct from an appeal to cognitive authority. In the case of $M$, an appeal to cognitive authority might look roughly like this:

\footnotetext{
${ }^{6}$ See also Friedman (1990, pp. 56-91).

${ }^{7} \mathrm{I}$ am grateful to an anonymous referee of this journal for making this point.

${ }^{8}$ See Goodwin (1998, p. 271).
} 
$M$ : Torturing animals is wrong.

$Q$ : Why?

$M$ : Because I say so, that's why.

As Goodwin points out (1998, p. 271), appeals to administrative authority are meant "to exert force." When an expert says "Do $A$," the audience is supposed to follow.

In the case of appeals to the authority of expertise, failure to follow would be deemed imprudent. As Goodwin (1998, p. 273) writes:

What do we say of the patient who did not take the pills prescribed or the juror who ignored the forensic scientist's testimony about the DNA evidence? Such a person seems to be acting unwisely, heedlessly, thoughtlessly - in a word, he is imprudent. We expect that imprudence will bring a penalty on itself: commonly, that the affair handled contrary to expert opinion will turn out badly on its own. Further, we are inclined to withdraw cooperation from the imprudent person, making it harder for him to accomplish his various projects.

For present purposes, then, the main question for consideration is the following: When is it not imprudent to fail to follow the advice of experts or the prescriptions of authorities?

It would not be imprudent to refuse to follow authority, I suggest, when the expert in question is involved in a practical inconsistency. To see why, consider the case of the moral philosopher again. Recall that the case under consideration is an appeal to M's authority in support of the imperative not to torture animals. To such an appeal to administrative authority, I suggest, the following seems to be a legitimate rebuttal:

(M1) $M$ says "Do not torture animals."

(M2) But $M$ is torturing animals in secret.

(M3) M's expert advice regarding the appropriate treatment of animals is inconsistent with her own treatment of animals.

(M4) M's status as an authority on matters pertaining to the proper treatment of animals has been put into question.

(M5) Therefore, it would not be imprudent to refuse to follow $M$ 's advice.

\footnotetext{
${ }^{9}$ See Schwitzgebel and Rust (2009). See also Maternowski (2009). Available at http://www.insidehighered.com/news/2009/06/16/ethics.
} 
What we have here, I suggest, is an ad hominem argument, since the attack is on the person. However, the attack is not a direct one on the character of the person, but an indirect one, citing her circumstances. That is, the premises of this argument cite circumstances of the expert in question, namely, that $M$ 's actions are at odds with her expert advice about the treatment of animals, as a reason why it would not be imprudent to fail to follow her advice.

There are two important points to keep in mind here. First, this circumstantial ad hominem argument seems to be legitimate only as a rebuttal to an appeal to administrative authority. That is to say, if we want to know whether to torture animals or not, and the only reason we have for not torturing animals is the expert advice of $M$, as an authority on animal rights, then, given the practical inconsistency between $M$ 's advice and her actions, it seems that we actually do not have a good reason not to torture animals. Of course, there might be other good reasons not to torture animals. However, the ad hominem argument outlined above shows that M's expertise is probably not one of them. To put it another way, suppose someone says, "Do not torture animals," and we ask "Why?" To reply, "Because $M$ says so," would not be a compelling response, since we could point out that $M$ 's expert advice is inconsistent with her actions.

Second, this form of argumentation is clearly defeasible. $M$ might try to contest it. In addition, as pointed out above, there might be other reasons why we should follow M's instruction not to torture animals, which have nothing to do with her expertise. That is precisely why this form of argumentation only works as a rebuttal to appeals to administrative authority. That is to say, it gives us a reason to think that refusing to follow M's advice would not be imprudent precisely because of her circumstances. Otherwise, we might ask ourselves, how is it that $M$, as an authority on animal rights, has argued that animals must not be tortured, and yet she is torturing animals herself? Does she not take her own expert advice seriously? If so, then it doesn't seem imprudent to refuse to heed her expert advice. In other words, her status as an authority, which is meant to exert force, seems to be undermined by the fact of practical inconsistency. ${ }^{10}$

On some occasions, I suggest, it might even be prudent to refuse to follow authority. Consider, for example, the case of a relig-

\footnotetext{
${ }^{10}$ One might think that moral imperatives, such as "Don't torture animals," pose a special problem as far as the attribution of expertise is concerned. What makes one an expert in such matters? See, e.g., Nickel (2001). That is why, in what follows, I consider examples of a different sort. I also address the objection regarding questionable authorities (see note 3 above) in Section 5.
} 
ious authority, such as the Minister Lee Jang-rim. On December 5, 1992, The Independent reported the following:

A 'doomsday' preacher was jailed for two years for defrauding his followers after persuading them the world would start coming to an end last October. Although Lee Jang-rim, 46, had apologised, he should be punished for the harm he caused his followers, Judge Soh Sang-kyu said. Many of Lee's followers quit their jobs, sold their homes, gave their assets to his church and left their families in the belief they would be lifted to Heaven before pestilence swept Earth. ${ }^{11}$

Subsequently, it became known that Lee Jang-rim had $\$ 800,000$ worth of bonds, which were not expected to mature until 1995, even though he predicted that the world would end on October 28, 1992. ${ }^{12}$ If what I said so far is correct, then Lee Jang-rim's followers could have reasoned as follows:

(L1) Minister Lee Jang-rim says that the world would come to an end in 1992, and thus that we should make certain preparations, such as quit jobs, sell homes, give assets away, etc.

(L2) But Lee Jang-rim is not preparing for the end of times (e.g., he has $\$ 800,000$ worth of bonds that are not expected to mature until 1995).

(L3) Lee Jang-rim's advice regarding the end of times is inconsistent with his actions.

(L4) Lee Jang-rim's status as a religious authority, especially in matters pertaining to the end of times, has been put in question.

(L5) Therefore, it would not be imprudent to refuse to follow Lee Jang-rim's advice.

This example seems to be a case where it would have been prudent to refuse to follow authority. As in the case of the moral philosopher discussed above, this is also an instance of a defeasible form of argumentation. As it turned out, Lee Jang-rim's claims about the end of the world were false and he was probably motivated by considerations that have nothing to do with the usefulness of his advice.

\footnotetext{
${ }^{11}$ Doomsday preacher jailed. The Independent. December 5, 1992. Available at http://www.independent.co.uk/news/world/doomsday-preacherjailed-1561574.html.

${ }^{12}$ Amor (1992). Available at http://www.collegian.psu.edu/archive/1992/10/10-22-92tdc/10-2292dops-column.asp.
} 
If his followers were to argue in the way I have suggested, not only would they not have argued fallaciously but they would have also saved themselves a lot of misery.

\section{Practice what you preach}

If the aforementioned considerations are correct, then ad hominem arguments are not always fallacious. When an appeal to (administrative) authority (of expertise) is made, it seems legitimate to respond by pointing out that the authority in question is acting in a manner that is inconsistent with her expert advice. If that is the case, then that is a good reason to think that failing to follow the advice would not be imprudent. Again, this is a defeasible form of argumentation, for there might be other reasons why the expert advice in question should be followed anyway. That is to say, other reasons might come to light that would decide the matter, i.e., whether the expert advice should be followed or not. But if we are urged to follow the expert's advice solely on the grounds that she is an expert in the matter at hand, then acting in a manner that is inconsistent with her own advice would put in question her status as an authority, and thereby give us a good reason to think that failing to follow her advice would not be imprudent.

As another example, consider the case of Al Gore. Al Gore is well-known for his documentary film on climate change, An Inconvenient Truth, among other things. In 2007, he was awarded the Nobel Peace Prize, along with the Intergovernmental Panel on Climate Change (IPCC), for "their efforts to build up and disseminate greater knowledge about man-made climate change, and to lay the foundations for the measures that are needed to counteract such change." "However, there are those who think that Al Gore is not as "green" as he says he is. Here is an example of the kind of charges leveled against Al Gore:

Graciously, Gore tells consumers how to change their lives to curb their carbon-gobbling ways: Switch to compact fluorescent light bulbs, use a clothesline, drive a hybrid, use renewable energy, dramatically cut back on consumption. Better still, responsible global citizens can follow Gore's example, because, as he readily points out in his speeches, he lives a "carbon-neutral lifestyle." But if Al Gore is the world's role model for ecology, the planet is doomed.

\footnotetext{
${ }^{13}$ The Nobel Foundation. The Nobel Peace Prize 2007. Available at http://nobelprize.org/nobel prizes/peace/laureates/2007/.
} 
For someone who says the sky is falling, he does very little. He says he recycles and drives a hybrid. And he claims he uses renewable energy credits to offset the pollution he produces when using a private jet to promote his film. (In reality, Paramount Classics, the film's distributor, pays this.)

Public records reveal that as Gore lectures Americans on excessive consumption, he and his wife Tipper live in two properties: a 10,000-square-foot, 20-room, eightbathroom home in Nashville, and a 4,000-square-foot home in Arlington, Va. (He also has a third home in Carthage, Tenn.) For someone rallying the planet to pursue a path of extreme personal sacrifice, Gore requires little from himself.

Then there is the troubling matter of his energy use. In the Washington, D.C., area, utility companies offer wind energy as an alternative to traditional energy. In Nashville, similar programs exist. Utility customers must simply pay a few extra pennies per kilowatt hour, and they can continue living their carbon-neutral lifestyles knowing that they are supporting wind energy. Plenty of businesses and institutions have signed up. Even the Bush administration is using green energy for some federal office buildings, as are thousands of area residents.

But according to public records, there is no evidence that Gore has signed up to use green energy in either of his large residences. When contacted Wednesday, Gore's office confirmed as much but said the Gores were looking into making the switch at both homes. Talk about inconvenient truths. ${ }^{14}$

Whether or not these charges against Al Gore are true, it seems that the argument can be reconstructed along the lines I suggested above:

(G1) Al Gore says that climate change is man-made, and thus that we must change our energy-consumption habits (e.g., drive hybrid cars, recycle, use renewable energy, etc.) in order to counteract it.

(G2) But Al Gore has not changed his own energyconsumption habits (e.g., he has a private jet).

(G3) Al Gore's advice regarding climate change and the way we should change our energy-consumption

\footnotetext{
${ }^{14}$ Schweizer (2006). Available at http://www.usatoday.com/news/opinion/editorials/2006-08-09-goregreen x.htm.
} 
habits in order to counteract it is inconsistent with his own habits.

(G4) Al Gore's status as an authority on climate change, especially on matters pertaining to energyconsumption habits, has been put in question.

(G5) Therefore, it would not be imprudent to refuse to follow Al Gore's advice.

Again, it is not clear that the charges leveled against Al Gore are true or even fair. But that is beside the point. The important point is that the argument outlined above is not fallacious. It seems to be a legitimate rebuttal to an appeal to Al Gore's authority as an expert in the matter at hand. As pointed out above, this kind of circumstantial ad hominem argument seems to be legitimate only as a rebuttal to an appeal to administrative authority. That is to say, if we want to know whether to change our energy-consumption habits or not, and the only reason we have for doing so is the expert advice of Al Gore, then, given the practical inconsistency between his advice and his actions, we actually do not have a good reason to change our energy-consumption habits. Of course, there might be other good reasons to do so. However, the ad hominem argument outlined above shows that Al Gore's expertise is probably not one of them. To put it another way, suppose someone says, "We should change our energy-consumption habits," and we ask "Why?" To reply, "Because Al Gore says so," would not be a compelling response, since we could point out that Al Gore's expert advice is inconsistent with his actions.

Again, it is important to note that this form of argumentation is defeasible. Al Gore might try to contest the charges leveled against him. In addition, as pointed out above, there might be other reasons why we should follow Al Gore's instruction to change our energyconsumption habits, which have nothing to do with his expertise. That is precisely why this form of argumentation only works as a rebuttal to appeals to administrative authority. That is to say, it gives us a reason to resist following Al Gore's advice precisely because of his circumstances. Otherwise, we might ask ourselves, how is it that Al Gore as an authority on measures to counteract climate change, has argued that we should change our energyconsumption habits, and yet he is not doing so himself? Does he not take his own expert advice seriously? If so, then it doesn't seem imprudent to refuse to heed his advice. In other words, his status as an authority, which is meant to exert force, seems to be undermined by the fact of practical inconsistency. 


\section{You contradict yourself}

As mentioned above, Walton (2004, p. 361) already pointed out that, when credibility as a source is a reason for accepting a claim, an attack on a person's character can undermine that person's credibility as a source. According to Walton (2004, p. 364), the form of the circumstantial ad hominem argument can be represented as follows:

$a$ advocates argument $\alpha$, which has proposition $A$ as its conclusion.

$a$ has carried an action or set of actions that imply that $a$ is personally committed to not- $A$ (the opposite of $A$ ).

Therefore, $a$ is a bad person.

Therefore, $a$ 's argument $\alpha$ should not be accepted. ${ }^{15}$

Walton (2004, p. 365) distinguishes this argumentation scheme from the one for the argument from inconsistent commitment (or, "you contradict yourself"):

$a$ is committed to proposition $A$ (generally, or in virtue of what she said in the past).

$a$ is committed to proposition $\sim A$, which is the conclusion of the argument that $a$ presently advocates.

Therefore, $a$ 's argument should not be accepted.

The argument from inconsistent commitment is thus different from the circumstantial ad hominem in that the former does not contain the personal attack premise that the latter does.

The treatment of circumstantial ad hominem arguments sketched in this paper can be viewed as essentially combining these two argumentation schemes. The attack, however, is not a direct attack on the expert's character, but an indirect one, via her circumstances, on her status as an authority. The result is the following argumentation scheme, which may be used legitimately as a rebuttal to appeals to (administrative) authority (of expertise):

Expert $e$, who is an authority on subject matter $S$, advises to do $D$.

But $e$ is not doing $D$.

$e$ 's advice to do $D$ is inconsistent with $e$ 's own actions.

$e$ 's status as an authority on $S$, especially on matters pertaining to $D$, has been put in question.

Therefore, it would not be imprudent to refuse to follow $e$ 's advice.

\footnotetext{
${ }^{15}$ See also Walton (2001, p. 212).
} 
Construed as a rebuttal to an appeal to administrative authority, this argumentation scheme contains a premise accusing the expert in question of practical inconsistency, and then concludes that, since her status as an authority has been undermined, it would not be imprudent to refuse to follow her advice.

Underlying this type of reasoning is a key assumption about practical inconsistency. As far as reasoning is concerned, having inconsistent commitments may be a serious allegation against an arguer. The treatment of circumstantial ad hominem arguments sketched in this paper, as legitimate rebuttals to appeals to authority, assumes that it is an even more serious allegation, perhaps even a fatal one, when the arguer in question is supposed to be an authority to which one appeals for support. Admittedly, this assumption can be questioned. However, it seems reasonable to say that, whereas engaging in practical inconsistencies is an understandable offense when laypersons are concerned, it is not so easily excused when experts are concerned. For experts are supposed to be able to avoid such inconsistencies in virtue of their expertise. That is to say, they are supposed to have such a mastery of the subject matter that would allow them to easily avoid these sorts of inconsistencies within their domain of expertise.

\section{Don't take my word for it}

At this point, it might be objected that all the experts discussed above - the moral philosopher, the doomsday preacher, and Al Gore - are not really experts at all. For instance, it might be wondered what makes one an expert in the appropriate treatment of animals. Moreover, how does being a moral philosopher qualify one as such an expert? Considering examples of genuine experts will show that ad hominem arguments are not legitimate. For example, consider an explosives expert who admonishes a curious spectator not to touch a sample of C4 because it is unstable and might go off. Even if we discover that this expert is engaged in reckless behavior with explosives, it is not clear that this practical inconsistency would undermine this expert's authority. ${ }^{16}$

In reply, it seems reasonable to say that what might seem to us - non-experts - as reckless behavior with explosives is actually not reckless at all. Indeed, precisely in virtue of her expertise, this expert knows what can and cannot be done with explosives. Other experts might also say that her behavior is not reckless after all, even though we might think it is, simply because we don't know how to safely handle explosives.

\footnotetext{
${ }^{16}$ I am grateful to an anonymous referee of this journal for making this objection and providing this useful example.
} 
In that case, however, it seems that there wouldn't be a practical inconsistency between the expert's advice and her actions. So, for the sake of argument, let's assume that other experts say that this expert's behavior is reckless. In that case, it seems to me that this kind of behavior does undermine this expert's authority as far as the appropriate handling of explosives is concerned. Recall that we want to know when it is not imprudent to fail to follow the expert advice of an authority. And, in this case, we have an expert whose behavior is deemed reckless, even in the eyes of other experts. This seems to undermine her authority, at least as far as the safe handling of explosives is concerned. To see why, consider the following exchange:

Expert A: Don't touch this sample of C4!

Spectator: Why?

Expert A: Because I say so, that's why!

Spectator: But you just touched this sample of $\mathrm{C} 4$.

Expert $A$ : I'm an expert. I know what I'm doing.

Spectator: But expert $B$ says that your handling of this $\mathrm{C} 4$ sample is reckless.

How might expert $A$ respond to this accusation of recklessness? The following seems to me a natural response:

Expert A: Well, don't take my word for it.

Notice how the authority of the reckless expert (expert $A$ ) has been undermined. Even if the spectator follows the advice not to touch the $\mathrm{C} 4$ sample, her reason for doing so would not be that the reckless expert $A$ says so, but rather that expert $B$ says so. To illustrate:

Expert A: Well, don't take my word for it. Expert $B$ also says not to touch this sample of $\mathrm{C} 4$.

Spectator: Well, in that case, I won't touch it, not because you say so, but because expert $B$ says so.

Using the argumentation scheme sketched in Section 4, then, we get the following:

(E1) Expert $A$ says "Don't touch this sample of C4!"

(E2) But expert $A$ is handling explosives recklessly and touching the $\mathrm{C} 4$ sample.

(E3) Expert $A$ 's advice regarding the safe handling of explosives is inconsistent with her actions.

(E4) Expert $A$ 's status as an authority on the safe handling of explosives has been put in question. 
(E5) Therefore, it would not be imprudent to refuse to follow expert $A$ 's advice.

If this is correct, then it shows that pointing out the practical inconsistency between expert $A$ 's advice to avoid touching the $\mathrm{C} 4$ sample and her reckless behavior with explosives has undermined her authority on matters pertaining to the proper handling of explosives. In other words, it seems that her authority no longer exerts the same force it might have exerted had it not been for the practical inconsistency.

\section{The road to hell is paved with good intentions}

In this section, I would like to discuss a familiar example from the literature in order to illustrate how the analysis sketched in this paper might lead to different results as far as the evaluation of ad hominem arguments is concerned. Considering this example will also serve to illustrate how the analysis sketched in this paper might be applied to other forms of authority, other than the authority of expertise, such as the authority of command and the authority of dignity.

The familiar example is the smoking example:

A parent argues to her child that smoking is associated with chronic disorders and that smoking is unhealthy, therefore the child should not smoke. The child replies "You smoke yourself. So much for your argument against smoking!"17

As a response to the argument that he should not smoke because smoking is unhealthy and associated with chronic disorders, the child's reply seems inadequate. Whether or not the parent is a smoker seems to be irrelevant to the association between smoking and chronic disorders. That association in itself, together with the fact that smoking is unhealthy in other respects, is a good reason not to smoke.

However, there is another way to interpret this example. It seems natural to think of the parent as an authority in this case, and thus that the parent's authority is meant to exert force. When a parent says, "Do $A$," a child is supposed to follow. Admittedly, the parent is not an expert on the association between smoking and chronic disorders. This is a matter for scientists and physicians to figure out. But the parent may be thought of as an authority of command, for the parent is the legal guardian of the child. Or the

\footnotetext{
${ }^{17}$ See, e.g., Walton (2010, p. 2).
} 
parent may be thought of as the authority of dignity. According to Goodwin (1998, p. 274), this is the kind of authority Locke (1975, pp. 611-612) had in mind when he wrote:

The first is, to allege the Opinions of Men, whose Parts, Learning, Eminency, Power, or some other cause has gained a name, and settled their Reputation in the common esteem with some kind of Authority. When Men are established in any kind of Dignity, 'tis thought a breach of Modesty for others to derogate any way from it, and question the Authority of Men, who are in possession of it, this is apt to be censured, as carrying with it too much of Pride, when a Man does not readily yield to the Determination of approved Authors, which is wont to be received with respect and submission by others: and 'tis looked upon as insolence, for a Man to set up, and adhere to his own opinion, against the current Stream of Antiquity; or to put it in the balance against that of some learned Doctor, or otherwise approved Writer. Whoever backs his Tenets with such Authorities, thinks he ought thereby to carry the Cause, and is ready to style it Impudence in any one, who shall stand out against them. This, I think, may be called Argumentum ad Verecundiam.

“To speak against dignity," according to Goodwin (1998, p. 275), "is not primarily disobedient or imprudent; rather, it shows disrespect, and ought to be a matter of shame." Goodwin argues that this is a third type of authority that is irreducible to the authority of expertise or the authority of command. Whether or not Goodwin is right about this is not important for present purposes. What is important, however, is that the kind of circumstantial ad hominem arguments discussed above seem to be legitimate rebuttals to appeals to (administrative) authority (of expertise), the kind of authority whose imperatives it would be imprudent to ignore. Now, the question is, can such circumstantial ad hominem arguments be legitimate rebuttals to the authority of dignity as well, the kind of authority whose imperatives it would be shameful to ignore?

This question may be answered in the affirmative, it seems to me, if we consider the parent to be an authority of dignity. If this is correct, then the child's argument can be construed as a rebuttal to the kind of appeal to authority discussed above:

Parent: Do not smoke!

Child: Why?

Parent: Because I say so, that's why! 


\section{Moti Mizrahi}

To this appeal to authority, the child's reply seems entirely appropriate.

Parent: Don't smoke!

Child: Why?

Parent: Because I say so, that's why!

Child: But you smoke, too.

The practical inconsistency between the parent's advice and actions seems to put in question her status as an authority (of dignity). In other words, given the practical inconsistency between the parent's words and her actions, it would not be shameful to ignore her imperative not to smoke. The child's argument, then, looks like this:

(P1) My mother says "Don't smoke!"

(P2) But she smokes herself.

(P3) My mother's advice is inconsistent with her actions.

(P4) My mother's status as an authority of dignity has been put in question.

(P5) Therefore, it would not be shameful to refuse to follow my mother's advice.

Again, this is a defeasible form of argumentation, and there may be other good reasons not to smoke. The child's ad hominem reply seems to be a legitimate rebuttal to this appeal to authority, however, for it shows that it would not be shameful to refuse to follow the mother's advice, given the practical inconsistency between her advice and actions.

I think we can get a similar result if we think of the parent in this case as an authority of command rather than dignity. While speaking against the authority of dignity is shameful, speaking against the authority of command is disobedient (Goodwin 1998, p. 275). Accordingly:

(P`1) My mother says "Don’t smoke!"

(P'2) But she smokes herself.

(P'3) My mother's advice is inconsistent with her actions.

(P`4) My mother's status as an authority of command has been put in question.

(P'5) Therefore, it would not be disobedient to refuse to follow my mother's advice.

As in the case of the reckless explosives expert, a natural way for the parent to respond to the child's accusation seems to be the following:

Parent: Well, don't take my word for it. 
If the parent responds in this way, then the argument is no longer an appeal to authority (i.e., the parent's authority). In other words, the parent is no longer using her authority to exert force on the child. Suppose that the parent urges the child to see a doctor. The doctor, of course, advises the child to give up smoking. As luck would have it, however, the doctor is a smoker, too. ${ }^{18}$

Doctor: Don't smoke!

Child: Why?

Doctor: Because I say so, that's why!

Child: But you smoke, too.

Does this accusation undermine in any way the doctor's authority? It might be argued that the doctor's advice is a good one, given with good intentions, and ought to be accepted. As such, it should not matter whether the doctor is a smoker or not.

Granted that the doctor gives advice in good faith, and that the advice to give up smoking is a good one regardless of the doctor's smoking habits, we must be careful not to lose sight of the basis or ground for the advice. For present purposes, we are interested in the argument as a whole, not just the piece of advice given. The argument in question is an appeal to (administrative) authority (of expertise). In other words, the child should give up smoking because the doctor says so. As in the case of the reckless explosives expert and the parent, a natural way for the doctor to respond to the child's accusation is the following:

Doctor: Well, don't take my word for it.

The doctor might then urge the child to read the medical research or seek a second opinion. But notice that, at this point, the argument is no longer an appeal to authority (i.e., the doctor's authority). In other words, the reason to stop smoking is no longer "because the doctor says so," but another reason, such as the research establishing an association between smoking and chronic disorders. At this point, however, we have a different argument on our hands, one to which a circumstantial ad hominem might not be a legitimate rebuttal. To illustrate:

Doctor: Don't smoke!

Child: Why?

Doctor: Because I say so, that's why!

Child: But you smoke, too.

\footnotetext{
${ }^{18} \mathrm{I}$ am grateful to an anonymous referee of this journal for making this objection and providing this useful example.
} 
Doctor: Well, don't take my word for it. Read the Surgeon General's Report.

Child: Well, in that case, perhaps I should give up smoking, not because you say so, but because the Surgeon General says so.

For the child's sake, we can only hope the Surgeon General is not a smoker, too.

\section{Conclusion}

In this paper, I discussed several examples that I take to be instances of non-fallacious ad hominem arguments. These arguments are instances of practical reasoning in which we argue from the circumstances of the person in question to a conclusion stating whether it would be imprudent or not to follow that person's advice. I argued that such circumstantial ad hominem arguments are legitimate when construed as rebuttals to appeals to the authority of expertise that puts forward imperatives. In other words, when presented with an argument from administrative authority, whose conclusion is to follow an expert's advice, it seems legitimate to point out that the expert's advice is not consistent with the expert's actions. If that is the case, then these circumstances would put in question the expert's status as an authority on the matter at hand, and thus provide a reason to think that it would not be imprudent to refuse to follow the expert's advice.

It must be emphasized that an expert's advice might be a good one, and given in good faith, even if the expert's words and actions are inconsistent. Such a practical inconsistency, however, does seem to undermine the expert's authority to some extent. In such a case, the audience might have a good reason to follow the expert's advice, but the reason would not be simply that the expert says so. For such practical inconsistencies seem to diminish the force that an authority is supposed to exert.

Acknowledgements: I wish to thank four anonymous referees of this journal for helpful comments on earlier drafts of this paper.

\section{References}

Adler, J. (2002). Belief's Own Ethics. Cambridge, MA: The MIT Press.

Amor, M. (1992). Fear and salvation endure as a means of control. The Daily Collegian Online. October 22, 1992. Available at 
http://www.collegian.psu.edu/archive/1992/10/10-22-

92tdc/10-22-92dops-column.asp.

Copi, I.M. \& Cohen, C. (1998). Introduction to Logic. Tenth Ed. Upper Saddle River, NJ: Prentice Hall.

De George, R.T. (1985). The Nature and Limits of Authority. Lawrence: University Press of Kansas.

Fox, R. (1972). Two Kinds of Authority. Philosophy in Context 1, 32-35.

Friedman, R.B. (1990). On the Concept of Authority in Political Philosophy. In J. Raz (Ed.), Authority (pp. 56-91). New York: New York University Press.

Goodwin, J. (1998). Forms of Authority and the Real Ad Verecundiam. Argumentation 12, 267-280.

Hoaglund, J. (1981). Argumentum Ad Hominem: Aut Bonum aut Malum? Informal Logic 4, 7-9.

The Independent. (1992). Doomsday preacher jailed. December 5, 1992. Available at

http://www.independent.co.uk/news/world/doomsdaypreacher-jailed-1561574.html.

Kitcher, P. (1993). The Advancement of Science. New York: Oxford University Press.

Locke, J. (1975). An Essay Concerning Human Understanding. Peter H. Nidditch (Ed.). Oxford: Clarendon Press. (Original work published 1689).

Mackenzie, P.T. (1980). Ad Hominem and Ad Verecundiam. Informal Logic 3, 9-11.

Maternowski, K. (2009). News: Do As I Say, Not As I Do. Inside Higher Ed. June 16, 2009. Available at http://www.insidehighered.com/news/2009/06/16/ethics.

Nickel, P. (2001). Moral Testimony and Its Authority. Ethical Theory and Moral Practice 4, 253-266.

Salmon, M.H. (2007). Introduction to Logic and Critical Thinking. Fifth Ed. Belmont, CA: Thomson Wadsworth.

Schweizer, P. (2006). Gore isn't quite as green as he's led the world to believe. USA Today. December 7, 2006. Available at http://www.usatoday.com/news/opinion/editorials/2006-08-09gore-green X.htm.

Schwitzgebel, E. and Rust, J. (2009). The Moral Behaviour of Ethicists: Peer Opinion. Mind 118, 1043-1059.

Walton, D. (1992). The Place of Emotion in Argument. Pennsylvania State University Press.

Walton, D. and Krabbe, C.W. (1995). Commitment in Dialogue: Basic Concepts of Interpersonal Reasoning. Albany: State University of New York Press.

Walton, D. (1996). Argumentation Schemes for Presumptive Reasoning. Mahwah, NJ: Lawrence Erlbaum Associates. 


\section{Moti Mizrahi}

Walton, D. (1997). Appeal to Expert Opinion: Arguments from Authority. University Park, PA: The Pennsylvania State University Press.

Walton, D. (1998). Ad Hominem Arguments. Tuscaloosa: The University of Alabama Press.

Walton, D. (2001). Searching for the Roots of the Circumstantial Ad Hominem. Argumentation 15, 207-221.

Walton, D. (2004). Argumentation Schemes and Historical Origins of the Circumstantial Ad Hominem Argument. Argumentation $18,359-368$.

Walton, D. (2010). Formalization of the ad hominem argumentation scheme. Journal of Applied Logic 8, 1-21.

Wilson, P. (1983). Second-hand Knowledge: An Inquiry into Cognitive Authority. Westport: Greenwood Press. 